\title{
VALOR-TRABALHO E TRABALHO IMATERIAL NAS CIÊNCIAS SOCIAIS CONTEMPORÂNEAS
}

\author{
Henrique Amorim*
}

\begin{abstract}
A teoria do valor foi até hoje lida com base em três recortes analíticos amplos. Um recorte anterior a Marx, o de Marx e dos marxistas e o dos neoclássicos. O anterior a Marx tem como elementos centrais a ideia de que o valor é uma categoria central das sociedades de economia mercantil ou de troca, que nas sociedades capitalistas ganharia sua expressão mais avançada no processo de criação da riqueza. Em Marx, o valor é considerado como a categoria econômica mercantil fundamental. No entanto, esse tipo de economia é apreciado como transitório, isto é, há uma determinação histórica da economia mercantil que se vincula diretamente à existência do valor. Já para os neoclássicos, o valor é uma categoria da atividade econômica em geral, sendo, portanto, a atividade econômica capitalista uma forma particular dessa atividade econômica geral. Sua preocupação central está, nesses termos, voltada para o equilíbrio geral apoiado na análise marginalista do valor. No entanto, o debate em torno do valor hoje parece ir além dessas classificações. Sua recuperação se sintetiza na seguinte pergunta: as teses sobre as novas tecnologias da informação e sobre o trabalho imaterial convergiriam para uma nova forma da teoria do valor-trabalho ou para a superação dessa teoria? O objetivo central deste artigo é caracterizar introdutoriamente as principais teses do debate na teoria social, que incorporam, atualizam ou negam a teoria do valor-trabalho no processo de análise do trabalho imaterial.

PALAVRAS-CHAVE: teoria do valor-trabalho, trabalho material e imaterial, Marx, sociologia contemporânea.
\end{abstract}

Um conjunto de fatores influenciou a crítica estrutural da teoria do valor-trabalho a partir dos anos 1970. Podemos delimitá-los, mesmo que esquematicamente, dividindo-os em duas frentes: uma histórica e outra teórica. A primeira delas se manifestou em decorrência do colapso de Bretton Woods e da crescente intervenção dos Estados nas políticas salariais, das crises do petróleo, do enfraquecimento progressivo das políticas de intervenção estatal de tipo keynesiano, da reestruturação produtiva (diminuição dos postos de trabalho na indústria dado pelo processo de automação), do desenvolvimento do neoliberalismo nos Estados Unidos e na Europa (já no fim da década de 1970 e início da década de 1980) e de sua nova política de regulamentação das leis de proteção ao trabalhador. No ao plano teórico, podemos destacar a emergência da teoria da "virada cultural", segundo a qual haveria a substituição da racionalidade econômica por uma racionalidade de tipo hedonista

\footnotetext{
* Doutor em Ciências Sociais pela UNICAMP. Professor de Sociologia da UNIFESP-Campus Guarullhos.

Estrada do Caminho Velho, 333. Bairro dos Pimentas. Cep: 07252-312. Guarulhos-SP. henriqueamorim@hotmail.com
}

- motivada, sobretudo, pela prosperidade dos países europeus sob o Estado de bem-estar social (Inglehart, 1997); das teorias dos novos movimentos sociais (Gohn, 2006; Offe, 1994) que, ao criticar o caráter redutor do paradigma produtivo, vislumbrava uma diversidade de processos de sociabilização para além do universo do trabalho; e da teoria da sociedade pós-industrial, que pressupõe a nova sociedade, pós-industrial, como uma sociedade na qual predominam valores pós-materialistas distintos daqueles das conjunturas precedentes, ancorados na economia e na indústria, e baseada, sobretudo, no setor de serviços (Bell, 1977).

Nesse contexto histórico-teórico, as teses de Marx e, particularmente, a teoria do valor-trabalho passaram a ser estruturalmente criticadas. No escopo geral dessa crítica está a ideia de que a teoria do valor-trabalho estaria relacionada ao industrialismo. ${ }^{1}$ Com a indicação do fim da ${ }^{1}$ Na prática, uma das formas de crítica à teoria marxista foi defini-la como uma teoria do industrialismo. Se esse último havia sido superado por novas e mais eficazes formas de produção, que faziam desenvolver a subjetividade do trabalhador e ainda mantinham as bases da produção capitalista, a teoria que dava sustentação ao "velho" embate entre classes sociais deveria ser considerada, no mínimo, uma teoria anacrônica ou ultrapassada (Gorz, 1987). 
"hegemonia" industrial, superada pelo setor de serviços e posteriormente pela financeirização da economia, a teoria do valor-trabalho foi designada como uma teoria historicamente ultrapassada.

Contudo, a partir do final dos 1990, com a crescente utilização de trabalhos nos quais predominam atividades não manuais, a teoria do valortrabalho volta à baila, sobretudo, nas análises sociológicas acerca do trabalho imaterial e das novas tecnologias da informação.

Essa recuperação da teoria do valor-trabalho vincula-se contemporaneamente a dois grandes pilares teóricos. O primeiro configura-se em torno das análises sobre o processo de transformação tecnológica na produção industrial, e também no setor de serviços, da diminuição do tempo de trabalho necessário à produção de mercadorias e da participação humana nas atividades concernentes às áreas tecnológicas mais desenvolvidas. O segundo, e como consequência do primeiro, relaciona-se ao crescimento do trabalho de tipo imaterial como força produtiva central.

A ideia geral é de que haveria um distanciamento das novas formas de trabalho (imaterial, informacional e cognitivo) ${ }^{2}$ em relação às atividades de constituição física dos objetos produzidos. O trabalho que tem como matéria-prima as capacidades cognitivas não poderia ser analisado pelo mesmo estatuto teórico daqueles trabalhos que têm como matéria-prima a produção material (no sentido físico do termo). Em resumo, a alusão de Marx ao homem transformando a natureza é confinada, apenas e tão somente, à ideia de natureza como conjunto de objetos físicos.

Como desdobramento dessa indicação acima descrita, a produção imaterial, como forma condensada de produção na qual predominariam as "capacidades intelectuais" da força de trabalho, coloca uma questão à teoria do valor como teoria da produção e da produtividade física das coisas. Se a teoria do valor de Marx é uma teoria que observa o processo de valorização apenas sob signo da transformação física da natureza, como seria

${ }^{2}$ Sobre a ideia de trabalho cognitivo e de capitalismo cognitivo, ver: Moulier-Boutang (2007). possível mensurar o tempo de trabalho necessário à produção imaterial? Sendo essa mensuração inviável, a teoria do valor perderia sua validade teórico-analítica? Seria o trabalho abstrato uma ficção, já que não possui uma natureza física? Ou ele sintetizaria a forma acabada das relações sociais capitalistas?

Tenho, nesse sentido, como objetivo, primeiramente, indicar que as teses sobre o trabalho imaterial e a teoria do valor são uma tentativa de atualização ou ruptura com a análise de Marx. Em segundo lugar, saliento que a distinção entre trabalho material e imaterial não faz parte da forma como Marx desenvolve sua crítica à produção capitalista, ou seja, ao separar trabalho material de imaterial, a sociologia, que trata do tema, criaria um falso problema.

\section{AREDESCOBERTA DA TEORIA DO VALOR}

As formas de utilização do trabalho desenvolvidas no último quarto do século XX e início do XXI, sintetizadas primeiro na figura do operário polivalente, da subcontratação, da redução relativa dos salários e, também, pelo consequente aumento do setor de serviços, motivaram, na teoria social, a reproblematização conceitual do trabalho e, especialmente, das teorias dos processos de produção e do valor-trabalho. A reestruturação produtiva foi objeto de variadas interpretações. Em linhas gerais, o acentuado processo de transformação da produção passou a ser considerado como um novo momento de reorganização da produção capitalista, responsável por alterar a dinâmica das relações sociais dentro e fora das empresas. Atualizar-se-iam as bases da reprodução social ao se alargarem as formas de exploração tanto das forças de trabalho ditas materiais e (ou) imateriais.

A polivalência e a formação profissional foram apresentadas como atributos básicos para o preenchimento de antigas ocupações profissionais que foram reorganizadas e também para as novas ocupações constituídas na nova conjuntura a partir de meados de 1970. O quadro de competências foi, 
portanto, ampliado. A utilização da força de trabalho de tipo fordista combinada à do trabalhador "recomposto" garantiria, dessa forma, maiores taxas de lucro. A assimilação de novas qualificações técnicas, a acumulação de funções de autocontrole administrativo e a definição de metas e de objetivos produtivos estariam diretamente relacionadas a esse quadro produtivo que se instalou, acabando por consagrar a ideologia empresarial baseada na perspectiva de um trabalhador participativo e submetido à ideia de parceiro, na qual estaria pressuposta a comunidade de objetivos e de interesses.

Com a reestruturação produtiva, as teses sobre a teoria do valor-trabalho são reproblematizadas tanto pela sociologia quanto pela economia. Esse esforço analítico deveu-se, pelo menos, a dois fatores que têm implicação recíproca: 1 - as modificações tecnológicas introduzidas nos processos de trabalho, somadas às novas formas de gestão e ao aumento do setor de serviços que, em conjunto, romperiam com as antigas formas de subordinação tradicionais da indústria, com a lógica de tempos e movimentos e da cadeia contínua de produção; 2 o conjunto dessas transformações faria surgir, mesmo como tendência, um novo tipo de trabalhador, que recuperaria o domínio de seu trabalho e do processo de trabalho. Estariam anunciados, com isso, o fim da hegemonia do trabalho manual e a reconstituição progressiva, no processo de produção, de elementos do trabalho intelectual. ${ }^{3}$

Nesse sentido, o conceito de trabalho imaterial dos Grundrisse de Marx (1980) passa a ser reexaminado vis-à-vis esse novo quadro tecnológico e gerencial. Uma nova problematização do trabalho e de como a sociedade seria ou não diretamente dele dependente ganha, portanto, importância. No entanto, essa leitura da imaterialidade é examinada em duas linhas excludentes: uma que afirma a validade da teoria do valor-trabalho no capitalismo contemporâneo, e outra que indica a incapacidade explicativa dessa teoria frente à dinâmica desse mesmo período.

${ }^{3}$ Nos termos de Fausto (1989), a substituição da subsunção formal-material do trabalho ao capital daria lugar à subsunção formal-intelectual do trabalho ao capital.

\section{MARX E O DEBATE SOBRE O TRABALHO IMATERIAL}

Marx definiu, em O Capital, o valor de troca como a expressão fenomênica do valor que é agregado à mercadoria com base na exploração do trabalho; ou melhor, no tempo médio de trabalho socialmente necessário para a produção de mercadorias. Assim, a medida do valor, para Marx, é o tempo de trabalho despendido na produção, é a utilização da força de trabalho na produção medida em unidades de tempo, sendo que esse valor é fruto das necessidades humanas, sejam elas originadas do estômago ou da fantasia (1988). Nesse sentido, Marx desenvolve a teoria do valor-trabalho como uma teoria da exploração do trabalho. Fundamenta-se, dessa forma, uma análise social que consagra a produção de mercadorias (materiais ou não) como seu objeto científico central e o trabalho abstrato como elemento decisivo para a valorização do capital.

A substituição de trabalho vivo por trabalho objetivado é considerada por Marx, nos Grundrisse (1980) e também em O Capital (1988), como a última forma social baseada no valor. A grande indústria desenvolveria, segundo Marx, o tempo de trabalho contínuo como medida e fator decisivo para a constituição da riqueza social (Marx, 1980). A diminuição do tempo de trabalho, como aquele necessário à produção de valores de troca, imporia, dentro dessa perspectiva, a superfluidade de parte desse tempo antes utilizado como tempo de extração de mais-valia. Haveria, com isso, uma transformação do espaço ocupado pelo homem no processo de produção. Constituir-se-ia uma desproporção entre o tempo de trabalho e seu produto, “... assim como uma desproporção qualitativa entre o trabalho, reduzido à pura abstração, e o poderio do processo de produção vigiado por aquele.” (Marx, 1980, p. 228).

O trabalhador apresentar-se-ia ao lado do processo, à margem; ele não seria mais o agente principal do processo de produção. Com base nessas indicações de Marx, realiza-se uma leitura do trabalho imaterial que acaba por requalificar a 
teoria do valor-trabalho. Em linhas gerais, essa requalificação vincula-se à ideia segundo a qual as novas formas de utilização do trabalho demandariam um novo tipo de trabalhador, cujos conteúdos comunicacionais, informativos, cognitivos, informacionais, em resumo, suas competências profissionais, deslocariam sua subordinação a um novo estágio político e social, estágio esse que romperia com a lógica de valorização do capital no momento em que os objetos produzidos pelos trabalhadores não seriam mais passíveis de quantificação.

Como expressão dessa leitura, Negri anuncia o trabalho imaterial da seguinte forma:

O trabalho imaterial - aquele que produz os bens imateriais como a informação, os saberes, as ideias, as imagens, as relações e os afetos - tende a tornar-se hegemônico. [...] o trabalho imaterial só pode ser realizado coletivamente, trocando informações, conhecimentos. [...] Toda pessoa que trabalha com a informação ou com o saber - do agricultor que desenvolve as propriedades específicas das sementes ao programador de softwares - utiliza o saber comum transmitido por outros e contribui para produzi-lo. (Negri, 2004, p. 44)

Há, nesse sentido, uma tentativa de reapropriação da teoria do valor-trabalho de Marx dentro de um ciclo ampliado de produção e reprodução sociais, não apenas relacionado à produção fabril, mas também à formação de um coletivo de trabalhadores inter-relacionados pela produçãoconsumo de conhecimentos, isto é, à constituição de um intelecto geral. A utilização do trabalho imaterial como força produtiva central seria, dessa forma, radicalizada, ao universalizar a utilização da subjetividade do trabalhador, fazendo reproduzir a subsunção real de sua condição social.

É o trabalho imaterial que ativa e organiza a relação social entre produção e consumo. A ativação, tanto da cooperação produtiva, quanto da relação social com o consumidor, é materializada nesse processo de comunicação (e, portanto, do trabalho e do consumo). Ela dá forma e materializa as necessidades, o imaginário, os gostos. A particularidade da mercadoria produzida pelo trabalho imaterial (seu valor de uso sendo essencialmente seu conteúdo informacional e cultural) consiste no fato de que ela não é atribuída no ato do consumo, mas ao contrário é alargada, transforma, cria o ambiente ideológico e cultural do consumidor. Seu valor de uso não repro- duz a capacidade física da força de trabalho, mas transforma seu usuário (Lazzarato, 1993, p. 114).

Em outros termos, Gorz qualifica mais sistematicamente sua análise do trabalho imaterial. ${ }^{4} \mathrm{Se}-$ gundo ele, a radicalização da produção de tipo imaterial parece levar a teoria do valor-trabalho à excrescência, pois indica uma contradição intransponível entre a lógica de universalização dos produtos imateriais e a mercadoria. Haveria, assim, um redimensionamento da forma histórica de valorização do capital nas sociedades economicamente avançadas. O capital tentaria incessantemente conservar, restringir o acesso, patentear o conhecimento presente nos produtos comercializados, mas não poderia fazê-lo por completo, pois fugiria do movimento intrínseco, ao capital, de acumulação e de extensão da exploração do trabalho. Portanto, como fundamenta Gorz, para produtos imateriais, essa lógica não faria mais sentido. A universalização dos produtos do trabalho imaterial acabaria por caracterizar o conhecimento formalizado e codificado como uma “não-mercadoria”, um bem comum. Assim, o movimento de independência do trabalho imaterial frente ao processo de acumulação de capital que este último - o capital - deveria conter, seria construído. A imensurabilidade, essa propriedade particular dos trabalhos imateriais, somente seria utilizada como fonte de um novo processo de valorização na medida em que ela fosse restringida. $\mathrm{O}$ monopólio do capital conhecimento (Gorz, 2005), por exemplo, sintetizaria a contenção dos produtos imateriais. Isto submeteria uma realidade ilimitada (dos produtos cognitivos) ao movimento limitado de troca de mercadorias.

Com a diminuição do trabalho imediato, as formas de pagamento e o valor de troca presente nas mercadorias seriam também reduzidos; isso produziria uma diminuição dos valores monetários, isto é, da riqueza e dos lucros produzidos. O capitalismo cognitivo apresentar-se-ia como momento de "crise do capitalismo em seu sentido mais estrito.” (Idem, 2005, p. 37). Nos termos de Gorz, o “capital conhecimento” "não é capital, no senti-

${ }^{4}$ Como contraponto à tese de Gorz, ver: Artous (2003). 
do usual, e não tem como destinação primária a de servir à produção de sobrevalor, nem mesmo de valor, no sentido usual." (Idem, 2005, p. 5455). Dessa forma, ele, o capital conhecimento, não se adequaria à norma tradicional de valorização e, ao mesmo tempo, desenvolver-se-ia como força produtiva central, apresentando-se, com isso, como momento de negação do capitalismo. O valor mercantil daria lugar a uma riqueza que não poderia mais ser regulamentada pelo capital. Por fim, essa separação formaria espontaneamente um processo de solidariedade e coletividade como vetor central de organização social (Idem, 2005, p. 57).

A desvinculação do trabalho imaterial das formas tradicionais de produção criaria uma negação em relação à produção tipicamente capitalista, uma vez que esse trabalho extravasaria a lógica da exploração de tempo de trabalho. Com isso, fundamentar-se-ia: 1- o fim da produção fundada no valor, pois, 2 - o processo de produção imediato perderia seu caráter forçado, compulsório, isto é, seu caráter antagônico, dessa forma, o objetivo da produção não seria mais reduzir o tempo de trabalho e aumentar o sobretrabalho, mas sim reduzir o trabalho necessário àquela parcela mínima que satisfaça as necessidades sociais. ${ }^{5}$

Em um sentido restrito, a tendência de substituição de trabalho vivo por trabalho passado e de incorporação da ciência e da tecnologia nesse processo estaria presente. Radicalizando a tese de Marx - segundo a qual "Como maquinaria, o meio de trabalho adquire um modo de existência material que pressupõe a substituição da força humana por forças naturais e da rotina empírica pela aplicação consciente das ciências da Natureza" (Marx, 1980, p. 15), coloca-se em xeque, primeiro, a necessidade de dependência da força de trabalho para a valorização de capital e, em segundo, ecomo consequência, a teoria do valor-trabalho como instrumento de análise teórico das economias capitalistas.

A relação entre processo de valorização do

\footnotetext{
${ }^{5}$ Gorz pressupõe, aqui, o fim das classes sociais, na medida em que sugere que a produção estaria baseada nas necessidades sociais, ou seja, no trabalho concreto, no valor de uso e não mais na necessidade de valorização do capital.
}

capital e a constituição social do capitalismo, como um fenômeno de existência recíproca e inseparável, teria sido um equívoco de Marx? Mais especificamente, o trabalho imaterial, como força produtiva central descolada da lógica de valorização do capital, seria exatamente a prova empírica desse equívoco? Ou o processo de valorização teria alcançado um novo estatuto distinto da materialidade pensada por Marx no século XIX? A imaterialidade seria mais uma nova fronteira de produtividade superada pelo capital, ou seja, seria outro universo produtivo submetido à lógica de valorização e acumulação capitalista?

\section{TEMPO DE TRABALHO E TRABALHO INTE- LECTUAL NAS ANÁLISES SOCIOLÓGICAS CONTEMPORÂNEAS DA TEORIA DO VALOR- TRABALHO}

A sociologia que discute o valor-trabalho hoje indica, em linhas gerais, uma configuração do trabalho radicalmente nova e não prevista pelas análises anteriores, calcadas, sobretudo, na análise do trabalho industrial, de seus processos de trabalho e na convergência de relações sociais de produção que contaminariam o modo de vida da sociedade como um todo. Dentro dessa discussão, a questão do tempo de trabalho e da utilização do trabalho intelectual como elemento central de reorganização da produção surgem como temas centrais às análises sociológicas e econômicas.

Um dos pontos mais discutidos é o da criação de tempo disponível com base na introdução de novas forças produtivas. Sua fundamentação teórica é caracterizada em contraposição à tese de Marx segundo a qual o capital, ao criar mais tempo disponível, criaria também mais tempo de maistrabalho. A produção de valores de troca apresentar-se-ia tendencialmente cada vez menos dependente do tempo de trabalho necessário. Entretanto, ainda só se fundamentaria como valor de troca, com base em quantidades dele mesmo (de tempo de trabalho) (Marx, 1980, p. 232).

Dessa forma, o tempo necessário como me- 
dida de trabalho deixaria de existir. O tempo disponível deixaria de ter uma forma antitética com relação ao tempo de trabalho, passando a ser governado por um tempo necessário, aquele pautado nas necessidades dos indivíduos sociais. Com isso, o desenvolvimento das forças produtivas sociais encontraria uma produção nunca antes vista e que, mesmo sendo calculada com base no interesse comum, ainda produziria tempo disponível, “... já que a riqueza real é a força produtiva desenvolvida de todos os indivíduos. O tempo de trabalho, já não é então, de modo algum, a medida da riqueza, mas sim o tempo disponível." (Idem, 1980, p. 232). O tempo de trabalho deixa de ser medida de valor, pois, por um lado, transforma a atividade do trabalhador em uma atividade de vigilância e regulação e, por outro, o produto do trabalho deixa de ser produto imediato, isolado, passando a ser uma combinação do trabalho social. A atividade social, nesse modelo analítico, substitui aquele conjunto de indivíduos que formava a figura produtora: o trabalhador coletivo.

De outro ponto de vista, as indicações de Marx sobre a supressão do trabalho vivo e sobre o aumento do trabalho passado fazem eco nas indicações sobre a impossibilidade do aumento do "emprego", haja vista a incorporação tecnológica cada vez mais intensa. A ampliação da produção de mercadorias não estaria apenas ligada à produção industrial; sua abrangência apresentar-se-ia como prerrogativa da nova lógica produtiva.

André Tosel, por exemplo, caracteriza um quadro social com base na análise dos "prestadores" de serviços, dos chamados autômatos de serviços. Os serviços seriam novas formas de utilização do trabalho que romperiam a divisão entre trabalho manual e intelectual. ${ }^{6}$ A qualificação intelectual

${ }^{6}$ Em termos conceitualmente mais rigorosos, não faz sentido falar em trabalho manual e intelectual. Nenhum trabalho é desprovido de um repertório cognitivo. A divisão conceitual absoluta entre trabalho manual e intelectual tem por fim o objetivo, não esperado, de estigmatização do trabalho, isto é, em vez de estabelece conceitos e noções mais densos, que possibilitem analisar as formas de trabalho e de exploração diferenciadas de trabalho, acabam por criar obstáculos a esse projeto.

Talvez, uma leitura menos maniqueísta das atividades ligadas aos processos de trabalho seja aquela de Harry Braverman (1980), na qual enfatiza tal divisão nos termos de concepção e execução do trabalho. projeta-se como fundamento da produção. Entretanto, o autor indaga: “... não seria o caso de situar (também) no mesmo espaço, a apropriação pelo capital das forças intelectuais?” (1994, p. 212). Para ele, a mercadoria força de trabalho, em sua forma supérflua, acaba por redefinir um estágio do desenvolvimento das forças produtivas (trabalho abstrato) que, em seu conjunto, poderia caracterizar a ruptura, mas que, contrariamente, encaminha a permanência das relações sociais capitalistas. Haveria, nesse sentido, uma continuidade do processo de valorização do capital e do trabalho como meio de realização dessa valorização. No entanto, o trabalho, na sua forma imediata, daria lugar às formas mediatas da atividade produtiva, estruturando-se uma expressão metamorfoseada do valor-trabalho.

A forma do valor tornar-se-ia cada vez mais a forma do valor trabalho intelectual-abstrato, ou seja, as formas de intelectualização da força de trabalho poderiam, assim, ser entendidas como razão primeira da valorização do capital. Flexibilidade, rapidez de deslocamento e autotransformação permanente caracterizar-se-iam e se autovalorizariam com base na incorporação constante do conhecimento retido como valor de troca. A cooperação, nesse sentido, tornarse-ia uma forma produtiva "processual".

A crescente "intelectualização" do trabalho, caracterizada pelo deslocamento da formação e de sua valorização da produção stricto sensu para outras áreas concernentes, muitas vezes, à administração e ao gerenciamento de fluxos de informação, faria aflorar novas possibilidades de domínio do coletivo de trabalho frente ao mando capitalista.

Do ponto de vista empresarial, a produção de um conhecimento específico deve ser "objetivada". Nesse sentido, as relações de troca aparecem como formas de automatização do trabalho intelectual, já que ele mesmo deveria ser objetivado como valor, através do dinheiro. Assim, parecem estar vinculadas a um projeto mais amplo de delegação de tarefas e serviços. Dentro dessa perspectiva, abre-se a questão do aumento da produtividade pela constante inserção de novas tecnologias à produção, o que tenderia a libe- 
rar uma quantidade de tempo de trabalho não mais necessária a determinada produção.

A questão que se coloca hoje à teoria do valor-trabalho como uma teoria da exploração exposta, particularmente, nos Grundrisse e em OCapital, é a seguinte: estaria Marx falando da formação de um coletivo de trabalhadores intelectualizados já no interior das sociedades capitalistas, de uma convivência entre duas forças realmente antagônicas ou tratar-se-ia de uma projeção teórico-histórica da transformação da produção em uma sociedade de novo tipo?

Um dos primeiros a tratar esse tema foi Marcuse, em seu livro A Ideologia da Sociedade Industrial (Marcuse, 1969). Sua opção é clara e se tornou hegemônica durante a segunda metade do século XX. Marcuse indica o processo de automatização como um desdobramento do progresso técnico. Não apenas como um processo quantitativo de acúmulo de forças produtivas. A automatização é concebida pelo autor como um conjunto de elementos que poderia catalisar a transformação estrutural da sociedade capitalista. A luta, no contexto do progresso técnico, poderia dar início e, nesse sentido, fundamentaria a forma de transgressão de um modo de produção a outro. "A automatização, ao se tornar o próprio processo de produção material, revolucionaria a sociedade inteira." (Idem, 1969, p. 53). Dessa formulação podemos identificar alguns de seus desdobramentos teóricos como, por exemplo, a tese do comunismo do saber de Gorz (2005, p. 10-11). ${ }^{7}$

Esse argumento - central para pensarmos o valor hoje - deve ser remetido a algumas problematizações importantes. A primeira delas seria a do desenvolvimento do capital fixo. Fausto (1989) vislumbra uma terceira forma de industrialização que, em conjunto com a manufatura e a maquinaria, fecharia a sequência lógica de desenvolvimento da sociedade capitalista e remeteria à criação de uma nova sociedade.

${ }^{7}$ Gorz (2005) também desenvolve essa tese no capítulo III: "Rumo a um comunismo do saber?...". Para um comentário crítico dessa tese de Gorz, ver Nicolas-le-Strat (1996/2, p.103) e Amorim (2009).
Com a industrialização, verificar-se-ia uma subsunção formal-material do trabalho ao capital. Com a formação da "pós-grande indústria", criarse-ia uma outra e terceira forma. "O homem não é mais sujeito do processo de produção. [...] O homem é de certo modo 'posto para fora', liberado (freigesetzt) do processo, mas é assim mesmo que ele passa a dominar o processo." (Idem, 1989, p. 52). A última reestruturação da produção, com base no desenvolvimento da automação, teria constituído uma nova condição de subordinação que não necessitaria mais de uma subordinação material do trabalho ao capital, isto é, na "pós-grande indústria", a subordinação material desapareceria, dando lugar a uma subordinação formal-intelectual do trabalho ao capital. (Idem, 1989, p. 60). Há, dessa forma, uma relativização da ruptura entre trabalho vivo e trabalho passado. A ciência contida na máquina a caracterizaria como uma força de trabalho intelectual, pois não necessitaria quase nunca de trabalho para estar em ação. A condição de vigia e supervisor da máquina não implicaria, assim, a existência ativa do trabalhador. "O autômato [diz Fausto] é agora autômato espiritual, não simples autômato “vivo"” (Idem, 1989, p. 58-59).

Dentro da mesma problemática, Prado (2004) indica que o desenvolvimento da grande indústria levaria o capitalismo a uma fase de transição, a "pósgrande indústria", na qual a produção não seria mais inteiramente dependente do tempo de trabalho. Com a grande indústria, instalou-se uma produção que, primeiro, estabeleceu a homogeneização dos produtos e, segundo, na qual a produtividade seria dada pela quantidade; um tipo de produção onde o tempo gasto é central, e sua redução um componente central para a estratégia capitalista de aumento da produtividade. Já na "pós-grande indústria", estabelecer-se-ia uma monstruosa heterogeneidade de produtos, sendo essa heterogeneidade determinada por uma produtividade pautada na qualidade e não na quantidade dos produtos. Não haveria, dessa forma, uma busca desenfreada pela redução do tempo de trabalho. Aproximar-nos-íamos de uma produção de tipo artístico, baseada no trabalho intelectual. 
As tecnologias introduzidas na produção de mercadorias, no entanto, parecem apontar para a requalificação de parte dos trabalhadores empregados. Para Barbrook, por exemplo, abre-se uma era cibernética, na qual estariam abertas novas possibilidades de superação do capitalismo (Barbrook, 2000). O conjunto de informações e técnicas empregadas pelos trabalhadores das indústrias de ponta faria constituir uma produção que estimula a apreensão cognitiva da produção. A produção, por necessitar desse tipo de qualificação, estimularia a formação de trabalhadores ultraqualificados. Projeta-se, assim, um retorno à lógica da manufatura, na qual o trabalhador controlava o processo de trabalho.

\section{NOTAS FINAIS}

O debate sociológico contemporâneo que estuda o tema do trabalho imaterial e da teoria do valor-trabalho relaciona indevidamente a produção de mercadorias do início do século XX às formas da produção atual. Ao relacioná-las, as qualificações técnica e profissional tornam-se uma panaceia. Delas fundamentam-se objetivos variados, tais como: a retomada do controle dos processos de trabalho pelo trabalhador coletivo, a constituição de um sujeito político consciente e, por fim, a superação das relações de produção capitalistas. Os conteúdos dos trabalhos materiais e imateriais são anunciados como políticos; eles carregariam consigo elementos antagônicos à ordenação social capitalista, caracterizando a constituição de uma política transformadora.

Essa tese advém de uma leitura sobre os conteúdos e significado dos trabalhos, segundo a qual a informação, por exemplo, somente conseguiria adquirir valor no momento em que fosse, na produção imaterial, reformulada, reorganizada, isto é, no momento em que fosse incorporada pelo produtor-consumidor. A ideia central seria a de que hoje o capital teria criado um problema sem solução. Ele passou, outra vez - como nos tempos dos mestres de ofício - a depender do trabalha- dor, do saber-fazer do trabalhador. O problema se colocaria, com isso, nos termos de uma dependência do capital em relação aos trabalhadores informacionais. O capital não poderia mais controlar os trabalhos imateriais, já que eles seriam "livres por natureza": a imaterialidade do trabalho foi, assim, considerada inapreensível (Gorz, 2007).

É com base nessa "nova” forma de compreensão do trabalho que se situa a discussão da retomada da teoria do valor-trabalho. Tempo de trabalho, qualificação profissional, atividades cognitivas, utilidade, caráter produtivo ou improdutivo do trabalho, imaterialidade, quantidadequalidade, domínio e controle da produção são elementos de um debate que se situa direta ou indiretamente sob a rubrica da teoria do valor-trabalho, ou pelo menos de como ela é recuperada pela sociologia contemporaneamente.

Gostaria, não obstante, de finalizar minha exposição das principais teses sobre a relação entre a teoria do valor-trabalho e as novas formas de trabalho indicando dois esclarecimentos que me parecem ausentes das considerações realizadas pelo escopo desse debate.

O primeiro deles está relacionado à forma como Marx encaminha a relação entre trabalho intelectual e trabalho manual. Essa relação acabou por motivar, no seio dos partidos comunistas e da teoria social influenciada por eles, classificações arbitrárias sobre quem pertencia ou não a uma determinada classe, sobre quais seriam os setores da classe mais aptos a realizar a revolução, quais seriam os mais adequados a ascenderem a uma suposta consciência de classe ou a triunfar em sua "missão histórica" de transformação estrutural da sociedade capitalista.

O segundo ponto está relacionado à questão da materialidade. Creio que a literatura marxista ortodoxa valeu-se de parâmetros físicos para compreender o que seria material ou não-material na produção e no trabalho. Por conseguinte, a bibliografia que se ergue nos anos 1970, em torno da ideia de superação do paradigma produtivo, acaba por responder a um falso problema. Ela parece ter sido, portanto, constituída em sinal inverso às te- 
ses do marxismo ortodoxo até então. Nesse sentido, reproduz-se uma oposição teoricamente ineficaz e não-dialética entre material e imaterial como eixo explicativo de todo debate nos anos que se seguem. Uma oposição que parece, de um lado, estar presente em dicotomias enrijecidas como as de trabalho produtivo e improdutivo, de trabalho intelectual e manual, de classe operária e classe trabalhadora na literatura marxista e, de outro, que figuram nos termos do trabalho cognitivo e trabalho manual, da sociedade do conhecimento e sociedade industrial, do capital imaterial e capital material.

É importante dizer que a divisão conceitual entre trabalho intelectual e trabalho manual mais dissimula que ajuda na compreensão das novas formas de trabalho. A relação central, na teoria de Marx, sobre o processo de valorização do capital se dá entre valor de uso e valor de troca. Os conceitos de trabalho manual e trabalho intelectual, ou mesmo de trabalho produtivo e trabalho improdutivo, devem ser examinados sempre com referência à relação entre valor de uso e valor de troca, trabalho concreto e abstrato.

A constituição do valor de troca e, posteriormente, do dinheiro como equivalente geral e mercadoria específica são os elementos que constituem a base do raciocínio de Marx sobre o processo de exploração do trabalho com o objetivo de ampliação da mais-valia relativa com base na redução do tempo de trabalho necessário e aumento da produtividade.

O trabalho abstrato é caracterizado, dessa forma, como um trabalho em geral que expressa diferentes quantidades de valores de troca das mercadorias, tornando-as socialmente intercambiáveis, tornando-se, portanto, um regulador das trocas de mercadorias distintas, isto é, com diferentes quantidades de tempo médio socialmente necessário para a sua produção. ${ }^{8}$

Dito isso, é possível projetar, na análise do autor, uma tendência de redução das formas de

${ }^{8}$ A mensuração do tempo médio de trabalho não está vinculada a uma equação matemática. Não se trata de uma média aritmética, que possibilite precisar a relação entre o tempo gasto na produção e a energia do trabalhador, mas apenas a quantidade de mercadorias produzidas. trabalho nas quais predominam as atividades de concepção. A análise histórica da passagem da manufatura à maquinaria caracterizou, para Marx, uma redução das formas de intervenção do trabalhador em relação ao como produzir. Em tendência, é possível, assim, concordar com Marx que a divisão do trabalho acentua progressivamente a subordinação do trabalhador em relação ao meio de trabalho dominado pelo capital.

Mesmo que as relações de produção já estejam consolidadas na manufatura, a forma típica de produção que permite o desenvolvimento da extração de mais-valia é a maquinaria. ${ }^{9}$ Nesses termos, é possível ler a história da produção capitalista como aquela da progressiva submissão do trabalhador à necessidade de o capital diminuir o tempo de trabalho necessário. No entanto, realizar uma divisão absoluta entre trabalho manual e trabalho intelectual pressupõe a completa e irrestrita subordinação dos subordinados e, com isso, a impossibilidade lógica destes recriarem suas condições de vida individual e coletiva, caracterizando, assim, também a impossibilidade relacional de sua atividade profissional, produtiva e política.

Se a relação social central, nas sociedades capitalistas, fundamenta-se na produção de mercadorias, e essas mercadorias se constituem pela relação de exploração baseada na extração de mais trabalho, produtivo é todo aquele trabalho ou coletivo de trabalho que esteja subordinado a essa relação, que tem como objetivo reproduzir as relações sociais que dão base à produção de valores de troca. ${ }^{10}$ É possível, ademais, admitirmos que o núcleo de extração de mais trabalho ainda hoje esteja vinculado à produção fabril. No entanto, isso não indica que a produção de coisas físicas seja a única a produzir sobretrabalho.

A rigor não há diferença conceitual entre a produção material ou imaterial. Essa dicotomia,

${ }^{9}$ Devo lembrar que as formas de gestão da empresa capitalista, mesmo que por Marx não tenham sido valorizadas, em minha compreensão, fazem parte da estrutura exploração do trabalho.

10 “ Le fait, pour le travail, d'être productif n'a absolument rien à voir avec le contenu déterminé du travail, son utilité particulière ou valeur d'usage particulère dans laquele il se matérialise.” (Marx, 1968, p. 393). 
na análise que Marx realiza da produção de mercadorias e do valor-trabalho, seria um falso problema. A produção de mais-valia, ou mais valor, não é caracterizada pela relação de transformação física dos objetos trabalhados. A teoria de Marx evidencia um conjunto específico de relações sociais que tem por característica central a produção de mercadorias sob um objetivo particular. O objetivo da produção capitalista, é bom que se frise, não é produzir valor, mas sim produzir um número maior de mercadorias em um tempo cada vez mais reduzido.

O valor-trabalho deve, então, ser considerado como um desdobramento das atividades e das relações sociais que engendram a produção capitalista. A discussão sobre a materialidade e a imaterialidade do trabalho pode ser relacionada muito mais à especificidade da produção capitalista, ou seja, ao objetivo de valorização do capital baseado na ampliação das mercadorias produzidas. Isto é, quanto maior for a produção (em um tempo menor), maior será a mais-valia relativa constitutiva do conjunto de mercadorias. As relações sociais que dão base e garantem essa empreitada sequer se valem da natureza física das coisas.

Não importa, desse modo, se estamos falando da produção de uma mercadoria conhecimento ou de uma mercadoria máquina. Pelo contrário, o importante é analisar como, em que condições, sob que tipo de empreendimento, em que encontro de relações sociais o conhecimento e a máquina foram produzidos. Em termos gerais, ambos podem ter sido produzidos na forma de uma mercadoria capitalista: redução do tempo global de produção com aumento de produtividade, gerando, com isso, uma diferença para cima entre o capital inicial e o final, informada pelo pagamento de um salário que não expressa o tempo total gasto na produção.

Nesses termos, inferir que a qualificação profissional do trabalhador, a matéria-prima trabalhada e os recursos utilizados representam, informam e constituem as relações sociais que estruturam o processo de trabalho não impõe a designação de uma materialidade que determina o conjunto de relações sociais. Qualificação, matéria-prima, ferramentas, máquinas, informações, softwares, etc. etc. são o resultado de relações sociais específicas. Todos eles são constituídos por relações de exploração e dominação sociais determinadas no terreno da estrutura social, isto é, das relações de classe.

Como desdobramento, não há lógica em afirmar que o valor-trabalho pode ou será transformado com a transformação das forças produtivas envolvidas no processo de produção de mercadorias, já que tais forças produtivas, em última instância, são expressão de relações sociais de produção cristalizadas. ${ }^{11}$ A materialidade é dada, então, pelo conjunto de relações sociais estabelecidas e não pela "fisicidade" dos elementos ativos em um processo de trabalho.

Falar em materialismo (histórico), portanto, não é simplesmente indicar o caráter tangível das coisas. É muito mais que isso: trata-se de reconhecer as relações efetivas que constituem nossa existência sob um determinado conjunto de relações sociais. A diferenciação entre material e imaterial não se relaciona, nesses termos, ao valor de troca, ao trabalho abstrato, mas sim ao valor de uso, ao trabalho concreto. Dessa forma, só faz sentido diferenciar a materialidade e a imaterialidade do trabalho quanto ao conteúdo do trabalho, e não quanto à produção do valor de troca, já que ele continua determinado pelo tempo de trabalho socialmente necessário à produção de mercadorias distintas. Em resumo, material ou imaterial, a valorização do capital tem fundamento na relação de troca entre mercadorias, isto é, em sua forma e não no conteúdo do trabalho empregado.

(Recebido para publicação em agosto de 2009) (Aceito em novembro de 2009)

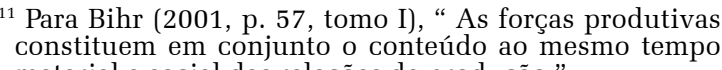
material e social das relações de produção.". 


\section{BIBLIOGRAFIA}

AMORIM, Henrique. Trabalho Imaterial: Marx e o debate contemporâneo. São Paulo: Annablume. 2009.

Teoria social e reducionismo analítico: para uma crítica a debate sobre a centralidade do trabalho. Caxias do Sul: EDUCS. 2006.

ARTOUS, Antoine. Travail et émancipation sociale: Marx et le travail. Paris: Éditions Syllepse. 2003.

BARBROOK, Richard. Le Cyber-communisme: ou le dépassement du capitalisme dans le cyberespace. Multitudes. v. 2, p. 186-199. 2000.

BELL, Daniel. O advento da sociedade pós-industrial: uma tentativa de previsão social. São Paulo: Cultrix. 1997.

BIHR, Alain. La reproduction du capital. Prolégomènes à une théorie générale du capitalisme. Paris: Editions Page Deux, 2001.

BRAVERMAN, Harry. Trabalho e capital monopolista: a degradação do trabalho no século XX. Rio de Janeiro: Zahar, 1980 .

DURKHEIM, Émile. De la division del trabajo social. Argentina: Schapire. 1973.

FAUSTO, Ruy. A pós-grande indústria nos Grundrisse (e para além deles). Lua Nova, v. 19, p. 47-67. 1989.

GOHN, Maria da Glória. Teorias dos movimentos sociais: paradigmas clássicos e contemporâneos. São Paulo: Loyola. 2006 .

GORZ, André. O Imaterial: conhecimento, valor e capital. São Paulo: Annablume. 2005.

Adeus ao proletariado - Para além do socialismo. Rio de Janeiro: Forense. 1987.

INGLEHART, Ronald. Modernization and postmodernization: cultural, economic, and political change in 43 societies. Princeton, NJ: Princeton University Press. 1997.
LAZZARATO, Maurizio. Le cycle de la production immatériel. Futur antérieur, v. 16, p. 114. 1993.

Le concept de travail immatériel: la grande entreprise. Futur antérieur, v. 10, p. 54-61. 1992/2.

LOJKINE, Jean. O novo salariado informacional. Nas fronteiras do salariado. Critica marxista, n. 25. 2007.

MARCUSE, Herbert. A ideologia da sociedade industrial. Rio de Janeiro: Zahar. 1969.

MARX, Karl. O capital. São Paulo: Nova Cultural. 1988.

. Elementos fundamentales para la crítica de la economia política (Grundrisse/Borrador). Buenos Aires: Siglo Veintiuno Argentina Editores. 1980.

Matériaux pour l'économie (Théories de la plus$\overline{\text { value), }}$ 1861-1865. In: Oeuvres. Paris: Gallimard/La Pleiade, v. 2. 1968.

MOULIER-BOUTANG, Yann. Le capitalisme cognitif: la nouvelle grande transformation. Paris: Editons Amsterdam. 2007.

NEGRI, Toni. De l'avenir de la democracie (débat avec Olivier Mongin). Alternatives Internationales. Paris, v. 18, p. 44. 2004.

NICOLAS-LE-STRAT, Pascal. Travail e constitution du sens à propos d'André Gorz. Futur antérieur, v. 35-36, p. 101-109. 1996/2.

OFFE, Claus. Capitalismo desorganizado: transformações contemporâneas do trabalho e da política. São Paulo: Brasiliense. 1994.

PRADO, Eleutério. Uma crítica à economia política do imaterial. Outubro, v. 11, p. 45-70. 2004.

TOSEL, André. Centralité et non-centralité du travail ou la passion des hommes superflus. In: Jacques Bidet \& Jacques Texier (Org.). La crise du travail. Paris: PUF. 1994. 


\section{LABOR-VALUE AND IMMATERIAL LABOR IN CONTEMPORARY SOCIAL SCIENCES}

\section{Henrique Amorim}

The theory of value was read until presently based on three broad analytical approaches. An approach before Marx, another approach by Marx and the Marxists and the neoclassicist approach. The one before Marx has as its central element the idea that value is a central category to societies with market or barter economy, that in capitalist societies would gain its most advanced expression in the process of wealth creation. In Marx, value is considered as the fundamental market economic category. However, this type of economy is assessed as transient, ie, there is a historical determination of the market economy that is directly linked to the existence of value. As for the neoclassicists, value is a category of economic activity in general, therefore, capitalist economic activity being a particular form of economic activity in general. Its main concern is, in these terms, directed to a general equilibrium supported by the marginalist analysis of value. However, the debate over value today seems to go beyond these classifications. Its recovery is summarized in the following question do theses on new information technologies and immaterial labor converge to a new form of labor theory of value or to overcome this theory? The main purpose of this paper is to introductorily characterize the main theses of debate in social theory, which incorporate, update or deny the labor theory of value in the process of analysis of immaterial labor.
Keywords: Labor Theory of Value, Labor, Material and Immaterial Labor, Marx, Contemporary Sociology.

\section{VALEUR TRAVAIL ET TRAVAIL IMMATÉRIEL DANS LES SCIENCES SOCIALES CONTEMPORAINES}

\section{Henrique Amorim}

Jusqu'à présent, la théorie de la valeur a toujours été analysée sur trois grandes périodes. La première se situe avant Marx, la deuxième correspond à celle de Marx et des marxistes et la dernière à celle des néoclassiques. L'idée phare de la période qui précède Marx est celle de la valeur considérée comme catégorie centrale des sociétés d'économie de marché ou d'échange qui, dans les sociétés capitalistes, trouveront leur plus grande expression dans le processus de création des richesses. Chez Marx, la valeur est l'élément fondamental de l'économie de marché. Toutefois, ce type d'économie est considéré transitoire car, historiquement, l'économie de marché est directement liée à l'existence de la valeur. Pour les néo-classiques, la valeur est une catégorie et fait partie de l'activité économique en général, l'activité économique capitaliste est donc une forme spécifique de cette activité économique générale. C'est-à-dire que sa préoccupation principale est celle d'un équilibre général basé sur l'analyse marginaliste de la valeur. De nos jours, le débat concernant la valeur semble toutefois aller au-delà de ces classifications. Son rétablissement pourrait être synthétisé par la question suivante: les thèses concernant les nouvelles technologies d'information et le travail immatériel convergent-elles vers l'élaboration d'une nouvelle théorie de la valeur travail ou vers le dépassement de cette théorie? L'objectif principal de cet article est de commencer à relever les caractéristiques des principales thèses sur le débat de la théorie sociale qui intègrent, mettent à jour ou nient la théorie de la valeur travail dans leur processus d’analyse du travail immatériel.

MOTS-CLÉs: théorie de la valeur travail, travail matériel et immatériel, Marx, sociologie contemporaine.

Henrique Amorim - Pós-Doutor em Sociologia pela UNICAMP e pela EHESS/Paris. Doutor em Ciências Sociais pela UNICAMP. Professor de Sociologia da UNIFESP-Campus Guarullhos. Autor dos livros: "Trabalho Imaterial: Marx e o Debate contemporâneo, publicado pela Ed. Annablume e "Teoria Social e Reducionismo Analítico: para uma crítica ao debate sobre a centralidade do trabalho", publicado pela EDUCS, além de diversos capítulos de livros e artigos em periódicos científicos. Atua predominantemente na área de Teoria Sociológica e Sociologia do Trabalho, trabalhando particularmente os temas: classes e estratificação sociais, valor-trabalho e trabalho imaterial. 